University of Nebraska - Lincoln

DigitalCommons@University of Nebraska - Lincoln

Social Responsiveness and Objectification: The Moderating Roles of Serotonin Transporter and Serotonin Receptor 2A Genotypes in an Objectification Theory Model of Disordered Eating

\author{
Grace A. Sullivan \\ University of Nebraska-Lincoln \\ Sarah J. Gervais \\ University of Nebraska-Lincoln, sgervais2@unl.edu \\ Rebecca L. Brock \\ University of Nebraska-Lincoln, rebecca.brock@unl.edu \\ Scott F. Stoltenberg \\ University of Nebraska-Lincoln, sstoltenberg2@unl.edu
}

Follow this and additional works at: https://digitalcommons.unl.edu/psychfacpub

Part of the Psychology Commons

Sullivan, Grace A.; Gervais, Sarah J.; Brock, Rebecca L.; and Stoltenberg, Scott F., "Social Responsiveness and Objectification: The Moderating Roles of Serotonin Transporter and Serotonin Receptor 2A Genotypes in an Objectification Theory Model of Disordered Eating" (2020). Faculty Publications, Department of Psychology. 1051.

https://digitalcommons.unl.edu/psychfacpub/1051

This Article is brought to you for free and open access by the Psychology, Department of at DigitalCommons@University of Nebraska - Lincoln. It has been accepted for inclusion in Faculty Publications, Department of Psychology by an authorized administrator of DigitalCommons@University of Nebraska - Lincoln. 
Published in Sex Roles 82 (2020), pp. 584-599; doi: 10.1007/s11199-019-01075-3

Copyright (C) 2019 Springer Science+Business Media, LLC. Used by permission.

Published online August 1, 2019.

Supplementary material follows the references.

\title{
Social Responsiveness and Objectification: The Moderating Roles of Serotonin Transporter and Serotonin Receptor 2A Genotypes in an Objectification Theory Model of Disordered Eating
}

\author{
Grace A. Sullivan, Sarah J. Gervais, Rebecca L. Brock, \\ and Scott F. Stoltenberg \\ Department of Psychology, University of Nebraska-Lincoln, Lincoln, Nebraska, USA \\ Corresponding author - Scott F. Stoltenberg, email sstoltenberg2@unl.edu
}

\begin{abstract}
Feminist scholars have called for gender researchers to consider gene-environment interactions for gender-imbalanced disorders (Salk and Hyde Psychology of Women Quarterly, 36, 395-411, 2012). Responding to these calls, the present study integrates objectification theory (Fredrickson and Roberts Psychology of Women Quarterly, 21, 173-206, 1997) and genetic research. In the tested model, objectification experiences are associated with disordered eating through body surveillance and body shame, and serotonin transporter (SLC6A4) genotypes (5-HTTLPR and rs25531), serotonin 2A receptor SNP genotypes (HTR2A rs6311), and the epistatic interaction between those genotypes function as moderators. U.S. undergraduate women $(n=526)$ completed self-reports of objectification, body surveillance, body shame, and disordered eating and donated buccal cells for genetic analyses. The association between objectification and disordered eating was mediated by body shame but not body surveillance. The paths from objectification to both body surveillance and body shame were moderated by genotypes. The indirect effect of objectification on disordered eating through body shame was present only for SLC6A4 L' and rs6311 G homozygotes. Our results are consistent with previous
\end{abstract}


evidence that serotonin system genetic variation is associated with disordered eating risk. They provide evidence of a nondeterministic genetic effect that is context dependent and subtle. These findings also reinforce efforts to develop personalized prevention and treatment approaches for eating disorders.

Keywords: objectification, serotonin, 5-HTTLPR, HTR2A, eating, genetics

Feminist theories and genetics theories are often perceived as taking opposing views on the nature versus nurture debate, with genetics being used to essentialize sex differences that tend to oppress women and to justify atrocities such as the involuntary sterilization of women motivated by the misguided eugenics movement (Black 2003). Yet modern genetic perspectives, especially with a focus on how genes and environmental factors interact, could reduce such dichotomous thinking, suggesting that genetic factors are not deterministic, but that genetic variation and experiences are inextricably and dynamically connected (Salk and Hyde 2012). Disordered eating (indicated by attitudes and behaviors that are characteristic of eating disorders) is a problem with known genetic and environmental contributions, and even subdiagnostic levels of eating disturbances and dieting frequency are related to depression and insecurity (Ackard et al. 2002); however, there is a lack of research integrating gender theories and genetics explanations of disordered eating. The present work aims to address this gap in the literature by examining gene-environment interactions by integrating objectification theory and genetics.

The relentless sexual objectification that women in Western cultures experience because of their gender, communicating that their physical appearance is the primary determinant of their value in the eyes of others, is known to put women at increased risk of disordered eating (Moradi and Huang 2008). Although disordered eating is prevalent in college women in the United States (Luce et al. 2008), many women do not present with eating disorders or even disordered eating. Similarly, genetic variation in the serotonin system is associated with disordered eating (Calati et al. 2011) but may be dependent on context. Thus, a more nuanced understanding of how contextual factors and individual differences contribute to the development of disordered eating in women is necessary. Toward that end, and in line with recent calls to feminist scholars to revisit genetic dispositions in a nondeterministic way (Salk and Hyde 2012), we provide a novel integration of objectification theory and research on genetic variation in the serotonin system to predict disordered eating. The present study tests a well-established pathway from objectification to disordered eating through body surveillance and body shame and investigates whether the pattern of results varies for women with different genotypes.

Understanding the combined effects of genetic variation and objectification offers both theoretical and practical implications. It could inform objectification theory, identifying additional, previously unspecified individual difference factors that influence women's responses to objectification. Although objectification is an occurrence that women experience disproportionately relative to men, there is also considerable diversity within gender with respect to objectification experiences (e.g., the consequences of objectification experiences vary as a function of age, weight, racial/ethnic identity, and chronic exposure to sexually objectifying environments; Grippo and Hill 2008; Liss and Erchull 2015). 
At a practical level, the obvious way to reduce disordered eating is to prevent sexual objectification from men toward women from occurring in the first place. In conjunction with these important efforts, it also may be valuable to identify genetic variants that are associated with women's susceptibility to objectification's effects, better characterizing the biological systems involved. Understanding how genetic variation and objectification experiences interact may help practitioners and policymakers develop interventions to reduce the negative consequences of objectification, even if objectification experiences remain high, which seems likely in patriarchal cultures that are saturated with heterosexuality. Additionally, identifying genetic factors that may impact responsivity to sexual objectification can help explain why some women, despite pervasive experiences of sexual objectification, do not exhibit disordered eating, although for others objectification plays a significant role in eating pathology.

\section{Objectification}

Sexual objectification occurs when a woman is reduced to her appearance, body, or sexual body parts or functions for the pleasure and consumption of the viewer (Bartky 1970; Nussbaum 1995). It manifests in interpersonal interactions through dehumanizing behaviors such as objectifying gazes, appearance commentary, and unwanted sexual advances (Kozee et al. 2007). College women report frequent experiences of sexual objectification (e.g., body gazes, appearance commentary; Kozee et al. 2007), which increase their risk for disordered eating (see Moradi and Huang 2008; Roberts et al. 2018, for reviews). The reasons for this relation are complex, but objectification theory (Fredrickson and Roberts 1997) posits that objectification experiences cause women to self-objectify, or see themselves as sexual objects through the eyes of third-party observers, and this self-objectification causes short-term (e.g., body shame) and long-term (e.g., eating disorders) health problems. Selfobjectification may be used as a strategy by women to determine how other people will treat them and as a means of establishing predictability and control in their everyday lives, given the persistent nature of objectification in their environment (Fredrickson and Roberts 1997).

Self-objectification can manifest in many ways, but one way that has been documented in the literature is through persistent body surveillance (routinely monitoring one's physical appearance; McKinley and Hyde 1996). Unfortunately, when women chronically scrutinize how they might appear to other people, they often experience body shame (the emotional reaction to feeling that one's body does not meet personal or social ideals of physical attractiveness). This process occurs because cultural ideals of beauty are unattainable for most women and comparing their perceptions of their bodies to those ideals leaves many women feeling inadequate (McKinley and Hyde 1996). This body shame may subsequently fuel behavioral efforts such as disordered eating as a means toward achieving this mostly unachievable appearance. Self-objectification contributes to women's disproportionate risk relative to men for unipolar depression, sexual dysfunction, and eating disorders (Fredrickson and Roberts 1997).

Empirical research using objectification theory as a framework shows that body surveillance and subsequent body shame mediate the relation between sexual objectification 
and disordered eating (Noll and Fredrickson 1998; Tiggemann and Slater 2001; Moradi et al. 2005). Additionally, self-objectification caused by awareness of unrealistic cultural standards of beauty is related to body-shame and disordered eating (Cashel et al. 2003; Griffiths et al. 2000; Heinberg et al. 1995; McKinley and Hyde 1996). Indeed, simply anticipating (without experiencing) objectification in the form of an imminent male gaze can increase body shame in college women (Calogero 2004). This convergent evidence provides empirical support that objectification can lead to body surveillance and body shame, which in turn can lead to disordered eating.

\section{Genetic Variation in Disordered Eating}

In addition to environmental contributors such as objectification, heritability estimates for clinical diagnosis of eating disorders range from 28 to 88\% (Hinney and Volckmar 2013). Furthermore, genetic variants in the serotonin system are implicated in risk for these disorders due to the association between serotonergic functioning and disordered eating (Calati et al. 2011; Favaro 2013). Variation in dopamine system genes (Nisoli et al. 2007), the Fat Mass and Obesity-Associated (FTO) gene (Castellini et al. 2017), and other genes have been associated with disordered eating (in individuals with eating disorders and healthy controls; see Yilmaz et al. 2015, for a review). However, due to the abundance of evidence implicating serotonin in disordered eating, as well as the likelihood of it interacting with environmental factors, the serotonin system is the focus of the present investigation. In animal and nonclinical human studies, for example, serotonin neurotransmission is associated with eating-related variables such as obesity and preference for carbohydrates and fat (Blundell et al. 1995; Leibowitz and Alexander 1998). In addition to medical issues that sometimes result from eating problems such as obesity, serotonergic functioning has been directly associated with disordered eating. Reduced serotonin neurotransmission is implicated in anorexia nervosa (Gauthier et al. 2014; Kaye et al. 2003), and serotonin-specific reuptake inhibitors (SSRIs) can be effective in treating eating disorders (Mitchell et al. 2013).

A polymorphism, called 5-HTTLPR, in the regulatory region of the serotonin transporter gene (SLC6A4), is associated with disordered eating in women (clinical and nonclinical samples) with genotypes indicative of lower serotonin transporter expression (for a review, see Calati et al. 2011), although not all studies replicate the finding (e.g., MunnChernoff et al. 2012). It is possible that the objectification that women experience in their environment may help explain these discrepant findings. For example, although women in general are more likely to have objectification experiences and to suffer worse consequences than men, there is also considerable variability with which women experience sexual objectification in their environment (Kozee et al. 2007; Moffitt and Szymanski 2011). Whether women with genotypes indicative of lower serotonin transporter expression develop disordered eating may depend, in part, on whether they have concomitant objectification in their environment.

The 5-HTTLPR genotype is most commonly composed of either short (S) or long (L) alleles and an additional single nucleotide polymorphism (SNP), either an A or G allele (rs25531). The $S$ allele is associated with lower transcriptional efficiency (i.e., the expression of fewer serotonin transporter proteins; Lesch et al. 1996), and when the L allele contains 
the $\mathrm{G}$ allele or rs25531 (LG allele), it has similarly low serotonin transporter expression (Hu et al. 2005). For this reason, the $L_{A}$ allele (referred to from here on as $L^{\prime}$ ) is distinguished from the $S$ allele or LG (both referred to as $S^{\prime}$ ). Carrying at least one $S^{\prime}$ allele is sufficient to reduce expression of the serotonin transporter gene compared to carrying the $\mathrm{L}^{\prime} / \mathrm{L}^{\prime}$ genotype (Hu et al. 2005; Zalsman et al. 2006).

The excitatory post-synaptic serotonin $2 \mathrm{~A}$ receptors, coded for by the HTR2A gene, also play a role in serotonin neurotransmission and eating pathology (Devlin et al., 2002). A single nucleotide polymorphism (SNP), rs6311, in the regulatory region of $H T R 2 A$ has an impact on its expression (Falkenberg et al. 2011; Smith et al. 2013), and both alleles have been associated with aspects of disordered eating. These findings indicate that the effect of genetic variation at this locus is highly sensitive to context. The G allele of rs6311 (which confers lower serotonin 2A receptor expression) is associated with higher reward dependence and harm avoidance in patients with anorexia nervosa (Rybakowski et al. 2006) and increased impulsivity with decreased sensitivity to post-synaptic serotonin in women with bulimia nervosa (Bruce et al. 2005). The A allele is generally associated with anorexia nervosa (Enoch et al. 1998, 1999; Martásková et al. 2009; Ricca et al. 2002), but not in all studies (Ando et al. 2001). There is substantial evidence for gene-gene interactions (known as epistasis; e.g., Stoltenberg et al. 2012a, b; Urwin and Nunn 2005), particularly when the genes code for proteins in the same system (such as the serotonin transporter and serotonin receptor 2A; Templeton 2000). Thus, epistatic interactions between rs6311 genotype and other genotypes (such as SLC6A4), as well as interactions with environmental factors (such as objectification), may contribute to inconsistencies in the literature because the effect of a particular genetic variation may be sensitive to the particular genetic and environmental context of a given study.

\section{Objectification Environments $\times$ Serotonin-Related Genes}

Although both objectification and genetic variation in the serotonin system are associated with disordered eating, there are individual differences in these associations. Some women experience objectification without concomitant disordered eating, and some women have genetic dispositions for disordered eating that are never expressed. With respect to objectification, for example, trying on a swimsuit in front of a mirror has been found to contribute to body shame, which in turn was associated with disordered eating, but primarily for women who were high on trait self-objectification (Fredrickson et al. 1998, Study 1). This and similar findings suggest that women high in self-objectification may be more responsive to the objectifying situation of trying on a swimsuit in front of a mirror than women low in self-objectification.

Genetic variation in the serotonin system has already been identified as a key component of individual differences in responsiveness to various social stressors (Zhou et al. 2008), or social responsiveness (SR). We hypothesize that higher SR conferred by certain genetic variants in the serotonin system could make sexual objectification in the environment more impactful for certain women, similarly to effects found with other social stressors (e.g., bullying and social exclusion; Sugden et al. 2010; Josephs et al. 2012). Sexual objectification experienced by women is ubiquitous and largely outside women's control 
(hence its oppressive power); yet, acknowledging that genetic differences may be associated with increased responsiveness to stressful social experiences such as sexual objectification could help researchers expand upon what is already known about within-gender variability in response to sexual objectification (e.g., Grippo and Hill 2008). Although women with low SR may be somewhat resilient to experienced objectification, objectification remains a significant problem for many women, and it may be particularly detrimental for women with high SR. Likewise, women with fewer objectification experiences may be somewhat resilient to developing disordered eating, even if they carry genes that can manifest in lower serotonin transporter expression.

Several genetic variants in the serotonin system, SLC6A4 and rs6311, are likely associated with SR because they have context-dependent effects. The S allele of SLC6A4 is associated with higher responsivity to several socially stressful experiences, such as bullying (Sugden et al. 2010), childhood maltreatment (Kaufman et al. 2006), and social exclusion (Josephs et al. 2012), whereas the $L$ allele is associated with higher responsivity to low socioeconomic status (Sadeh et al. 2010). Evidence associating the $\mathrm{G}$ allele of rs6311 with context-dependent disorders such as seasonal affective disorder (Molnar et al. 2010) and post-traumatic stress disorder (Lee and Lin 2010; Mellman et al. 2009), as well as evidence for increased potential for epigenetic changes in the G allele (Falkenberg et al. 2011), suggest that the G allele is also associated with sensitivity to environmental impacts (cf., Enoch et al. 1999). These genetic variants in the serotonin system likely play roles in responsiveness to a variety of stimuli (e.g., early life stress) in the development of multiple outcomes (e.g., depression), but the heretofore untested association with these genetic variants and objectification-related outcomes is of particular interest in the current study.

Objectification can be conceptualized as a social stressor that exist in patriarchal cultures and disproportionately affects women relative to men. Consistent with this social stressor lens, objectification theory suggests that objectification experiences result in appearance anxiety (Fredrickson and Roberts 1997), and researchers have suggested that objectification is a stressful form of discrimination that can lead to psychological distress and undermine physical health (Moradi 2013). There also is research showing that objectification experiences contribute to safety concerns (Fairchild and Rudman 2008) as well as anxiety (Davidson et al. 2016; Donnelly and Calogero 2017), providing empirical evidence that objectification is experienced as stressful to many women. Considered with research on outcomes associated with the SLC6A4 and rs6311 genotypes, it is possible that the SLC6A4 genotype, the rs6311 genotype, or both may moderate associations between objectification and its correlates with disordered eating.

\section{The Present Study}

The present model tested moderation of the pathway from objectification to disordered eating by genotypes. Both SLC6A4 genotype and rs6311 genotype are associated with differential responsiveness to certain environmental stressors (Josephs et al. 2012; Mellman et al. 2009), and objectification is experienced as stressful (Davidson et al. 2016; Donnelly and Calogero 2017), so both genotypes may moderate responsiveness to sexual objectification. The direction of these effects, however, is unclear. Thus, the present investigation is 
exploratory in nature with respect to which combination of genotypes is likely to be associated with the greatest likelihood for sexual objectification to manifest in disordered eating. Because of the likelihood of epistasis between SLC6A4 and rs6311 (Templeton 2000), and consistent with recommendations to include all two-way interactions when testing a three-way interaction (Hayes 2013), the interaction between the genotypes is also included as a possible moderator.

The proposed pathway from objectification to disordered eating through body surveillance and body shame is based on empirical support for objectification theory. The current study comprehensively tested genetic moderation from objectification to eating problems to account for conditional effects throughout the model. The paths from objectification to body surveillance (path A), body shame (path D), and disordered eating (path F) may be moderated by genotypes based on our hypothesis that SLC6A4 genotypes, rs6311 genotypes, and their epistatic interaction may be associated with differential responsiveness to objectification. Although objectification experiences in social interactions are one specific stressor that may be differentially impactful based on genotype, related body surveillance and body shame are likely manifestations of several environmental stressors (including interpersonal objectification but also objectification in media, exposure to traditional gender role stereotypes, and social comparison). Thus, we also examined whether the paths from body surveillance to body shame (path B), body shame to disordered eating (path C), and body surveillance to disordered eating (path $\mathrm{D}$ ) may be moderated by the genotypes. There is indeed some evidence that self-consciousness and shame can be differentially impactful for people with different SLC6A4 genotypes, based on physiological arousal (Gyurak et al. 2013), so it is worth testing whether these differential impacts also occur in the association with disordered eating. This model provides a first step in testing the role that genetic variation may play in individual differences in the pathway from objectification to disordered eating.

\section{Method}

\section{Participants and Procedures}

A total of 539 undergraduate women from the psychology research pool at a large U.S. Midwestern university participated for course credit, each receiving one credit for 30 minutes of participation. Thirteen participants were excluded from analyses due to missing genotype data, so the total sample size was 526 . Participants were primarily White (414, 78.7\% White; 18, 3.4\% Black; 2, .4\% Native American; 30, 6.1\% Hispanic; 20, 3.8\% multiracial or other) and heterosexual (484, $92.0 \%$ heterosexual; $10,1.9 \%$ bisexual; $19,3.6 \%$ gay/lesbian; $4, .8 \%$ pansexual/demisexual/asexual/other), with ages ranging from 18 to 40 years old $\left(M_{\text {age }}=20.28, S D=2.29\right)$ and body mass index (BMI) ranging from 14.24 to 48.65 (Мвм $=23.34, S D=4.71$ ). Participants gave informed consent, completed questionnaires, and donated buccal cells for genetic analyses. DNA was extracted from buccal cells and genotypes were determined for 5-HTTLPR, rs25531, and rs6311. The present study was approved by the university's Institutional Review Board. DNA samples were stored in a locked lab until disposal after the completion of all analyses. 


\section{Measures}

Sexual objectification was measured using the Interpersonal Sexual Objectification Scale (ISOS; Kozee et al. 2007). Participants rated the frequency with which they have experienced 15 items on a scale from 1 (never) to 5 (almost always) in the past year. Sample items include: "How often have you been whistled at while walking down a street?" and "How often have you been touched or fondled against your will?" Mean scores were calculated for the full scale with higher scores representing greater levels of sexual objectification. This scale was selected because previous psychometric data and associations with theoretically related constructs suggest good validity and reliability. The ISOS has been structurally validated with exploratory and confirmatory factor analysis and has been found to be associated with sexist degradation, sexist events, body surveillance, and body shame (Kozee et al. 2007). Previous psychometrics report internal consistency of 92 and test-retest reliability of .90 across a 3-week period (Kozee et al. 2007). Cronbach's alpha for the current sample was .92.

Body surveillance and body shame were measured using subscales of the Objectified Body Consciousness Scale (OBCS; adapted from McKinley and Hyde 1996). Participants indicated agreement with items on two subscales (each consisting of eight items) using a Likert scale from 1 (strongly disagree) to 6 (strongly agree). The Body Surveillance subscale measures people's tendencies to habitually monitor their bodies and think about appearance and includes items such as "I rarely think about how I look" (reverse coded). The Body Shame subscale measures one's tendency to feel shame when one's body does not conform to expected standards and includes items such as "When I can't control my weight, I feel like there is something wrong with me." Negatively worded items were reverse coded, and mean scores from each subscale were calculated and analyzed separately, with higher scores indicating more body surveillance and more body shame, respectively. These subscales have demonstrated good internal consistency ( $\alpha=.89$ for Surveillance; $\alpha=.75$ for Body Shame) and has been supported by both exploratory and confirmatory factor analysis. Body Surveillance and Body Shame are valid measures, based on each showing the expected associations with body esteem and disordered eating and body surveillance showing convergent validity with public self-consciousness and discriminant validity from social anxiety (McKinley and Hyde 1996). Internal consistencies for the subscales for the current sample were good ( $\alpha=.76$ for Body Surveillance; $\alpha=.85$ for Body Shame).

Disordered eating was assessed using the Eating Attitudes Test (EAT-26; Garner et al. 1982). On this 26-item self-report questionnaire, participants respond on a Likert-type scale from 1 (never) to 5 (always). This response structure for the EAT-26 has been shown to provide good variability, particularly in nonclinical samples (Maïano et al. 2013). The questionnaire consists of three subscales: Dieting ("I am aware of the calorie content of foods I eat"), Bulimia and Food Preoccupation ("I find myself preoccupied with food"), and Oral Control ("I avoid eating when I'm hungry"; Ocker et al. 2007). EAT-26 total scores were calculated by summing the items. Higher scores indicate more characteristics of eating disorders. This scale has demonstrated good internal consistency ( $\alpha=.94$; Garner et al. 1982), has been supported and revised through factor analysis, and has been correlated to body- 
image variables and eating disorder diagnoses (Garner et al. 1982; Maïano et al. 2013). Internal consistency for the current sample was good $(\alpha=.90)$.

For exploratory purposes, participants were also asked four additional questions which are not part of the EAT-26: "Have you gone on eating binges where you feel that you may not be able to stop? (Eating much more than most people would eat under the same circumstances)"; "Have you ever made yourself sick (vomited) to control your weight or shape?"; "Have you ever used laxatives, diet pills or diuretics (water pills) to control your weight or shape?"; and "Have you ever been treated for an eating disorder?" These items were included to further describe our sample's self-reported eating behaviors.

\section{DNA Processing}

DNA was extracted from lysed buccal cells and genotyped for 5-HTTLPR, rs25531, and rs6311 using standard procedures (Wendland et al. 2006; detailed DNA processing procedures are provided in the supplementary material). Participants with highest functioning SLC6A4 genotypes (L/L on 5-HTTLPR and A/A on rs25531; L'/L') were grouped for analysis and compared to anyone carrying a low-functioning allele (S on 5-HTTLPR and/or G on rs25531; $\left.\mathrm{S}^{\prime} /{ }_{-}\right)$.

\section{Data Analytic Strategy}

The model shown in Figure 1 was tested using maximum likelihood (ML) estimation with Mplus software (Muthén and Muthén 2010), testing all potential direct and indirect pathways between objectification and disordered eating as well as testing for moderation of SLC6A4 genotype, rs6311 genotype, and the epistatic interaction for all paths. Quantitative predictor variables were mean-centered (see means used for centering in Table 1). There were missing data for 13 participants (all missing at least one genotype call), and these participants were dropped from the analysis. For SLC6A4 genotype, $\mathrm{L}^{\prime} / \mathrm{L}^{\prime}$ was coded as 0 , and $S^{\prime}$ carriers were coded as 1 (based on transcriptional efficiency; Hu et al. 2005; Zalsman et al. 2006). For rs6311 genotype, G/G was coded as 0 , and A carriers were coded as 1 ; because the A allele is significantly less common, comparing anyone who carries at least 1 copy of the A allele to G allele homozygotes helps with statistical power. 


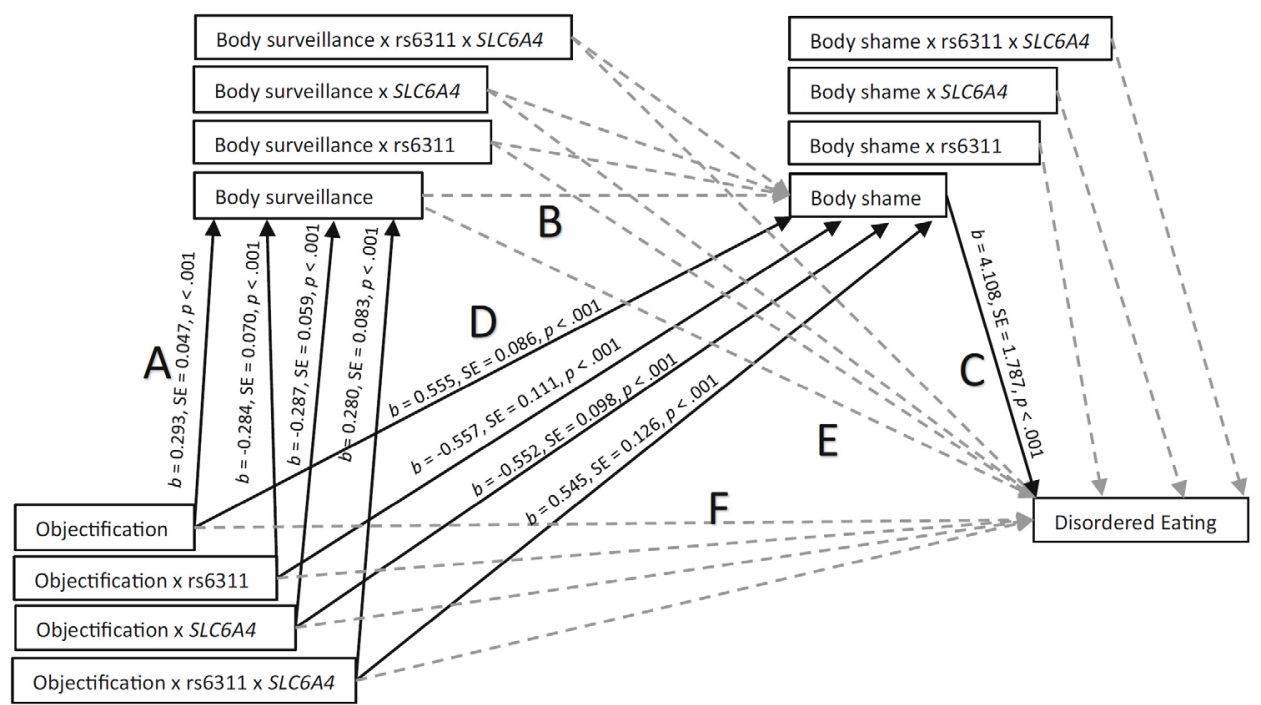

Figure 1. Model with significant coefficients. The only significant paths were from objectification $\rightarrow$ body surveillance, objectification $\rightarrow$ body shame, and body shame $\rightarrow$ disordered eating. The paths from objectification to body surveillance and from objectification to body shame were moderated by genotype, so coefficients shown for these paths indicate the effect for women with SLC6A4 L'/L' genotypes and rs6311 G/G genotypes (groups coded 0 ). Nonsignificant paths are indicated by gray dashed paths. Main effects of genotypes, their epistatic interaction, covariates (age, race/ethnicity, BMI) and genetic interactions with covariates are also included as predictors at all paths, but are not shown.

Table 1. Descriptive statistics, sample sizes, and correlations among study variables

\begin{tabular}{|c|c|c|c|c|c|c|c|c|c|c|}
\hline & $M(S D)$ & $n$ & 1 & 2 & 3 & 4 & 5 & 6 & 7 & 8 \\
\hline 1. Objectification & $2.25(.55)$ & 539 & - & & & & & & & \\
\hline 2. Body Surveillance & $3.83(.77)$ & 539 & $.142^{* *}$ & - & & & & & & \\
\hline 3. Body Shame & $2.80(.99)$ & 539 & $.158^{* *}$ & $.503^{*}$ & - & & & & & \\
\hline 4. Disordered eating & $13.86(9.81)$ & 536 & $.171^{* *}$ & $.371^{*}$ & $.627^{* *}$ & - & & & & \\
\hline 5. SLC6A4 genotype & - & 532 & $-.090^{*}$ & -.011 & -.073 & .084 & - & & & \\
\hline 6. rs6311 genotype & - & 532 & -.012 & -.016 & -.045 & -.032 & .042 & - & & \\
\hline 7. Race/Ethnicity & - & 539 & .027 & -.001 & -.017 & -.009 & .059 & .030 & - & \\
\hline 8. Age & $20.28(2.29)$ & 538 & $.187^{* *}$ & -.025 & $.085^{*}$ & .046 & -.045 & .021 & .036 & - \\
\hline 9. BMI & $23.34(4.71)$ & 538 & .013 & $.113^{*}$ & $.266^{* *}$ & .064 & .001 & .010 & -.021 & $.169^{* *}$ \\
\hline
\end{tabular}

$\mathrm{BMI}=$ Body Mass Index. For SLC6A4 genotype, $\mathrm{L}^{\prime} / \mathrm{L}^{\prime}$ was coded as 0 and $\mathrm{S}^{\prime}$ carriers were coded as 1 . For rs6311 genotype, G/G was coded as 0 and A carriers were coded as 1.For race/ethnicity, White was coded as 0 and all other responses were coded as $1 .{ }^{*} p<.05,{ }^{* *} p<.01$ 
Age, race/ethnicity, BMI, and interaction terms between each of these variables and each genetic variable were included as covariates in the model (Dick et al. 2015). Global model fit was assessed with Comparative Fit Index (CFI), TuckerLewis Index (TLI), Root Mean Square Error of Approximation (RMSEA), and the Standard Root Mean Residual $(S R M R)$ prior to interpretation of path coefficients. Bootstrapped confidence intervals ( $95 \%$ CIs) derived from 5,000 bootstrap draws were used to probe for conditional indirect effects, which helps account for bias due to nonnormality (Muthén 2011).

\section{Results}

Univariate statistics are shown in Table 1 and are in line with previous samples of college women (e.g., Calogero et al. 2010), and demographic statistics are also representative of the university at which data were collected, aside from the exclusion of men from the present study. Quantitative variables were relatively normally distributed, ISR skew $=.26$, ISR kurtosis $=.12$, body surveillance skew $=.02$, body surveillance kurtosis $=-.33$, body shame skew $=.50$, body shame kurtosis $=-.08$, EAT-26 skew $=1.61$, EAT-26 kurtosis $=3.46$. To determine whether univariate or multivariate non-normality introduced significant bias into the model, we ran the model using robust maximum likelihood estimation (MLR) and demonstrated the same pattern of results.

Responses to the descriptive eating behavior questions revealed that during their lifetimes, $15.7 \%(n=83)$ reported binge eating; $8.2 \%(n=44)$ reported vomiting to control their weight; $18.2 \%(n=96)$ reported using laxatives, diet pills, or diuretics to control their weight; and $4.1 \%(n=22)$ reported having been treated for an eating disorder. Bivariate correlations are shown in Table 1. Bivariate associations confirmed our hypotheses that objectification, body surveillance, body shame, and disordered eating are all significantly and positively associated with each other. Bivariate associations between genotypes and other variables were nonsignificant, except for a weak association $(r=-.09)$ revealing increased objectification reported by women with the $\mathrm{L}^{\prime} / \mathrm{L}^{\prime}$ genotype. The general lack of bivariate associations with genetic variables underscores the importance of considering environmental context when investigating genetic risk factors. The slight increase in report of objectification for women with the $\mathrm{L}^{\prime} / \mathrm{L}^{\prime}$ genotype was not significant after controlling for other variables in the model. None of the bivariate correlations exceeded .70, so there were no concerns about multicollinearity.

Global fit of the full model with all indirect and moderating effects was adequate, based on the CFI $=.94$ (value of .90 or higher indicates adequate fit; Bentler 1990), TLI $=.96$ (value of .90 or higher indicates adequate fit; Tucker and Lewis 1973), RMSEA $=.05,90 \%$ CI [.05, .06] (values greater than .10 indicate poor fit; Browne and Cudeck 1992), SRMR $=.07$ (values greater than .10 indicate poor fit; MacCallum et al. 1996). Although the model Chisquare statistic was significant, $\chi^{2}(118)=299.18, p<.0001$, this effect was anticipated given the size of the sample. Notably, there are different perspectives regarding ideal thresholds for fit indices (e.g., Barrett 2007; Hayduk et al. 2007); however, collectively, the fit indices suggested adequate fit, and there were no theoretically meaningful modifications to the model (Brown 2015). As such, we retained the model in its current form. The model accounted for $38.2 \%(S E=.10, p<.001)$ of the variance in disordered eating, 48.4\% $(S E=.09$, 
$p<.001)$ of the variance in body shame, and $4.3 \%(S E=.02, p=.01)$ of the variance in body surveillance.

Of the 539 participants who enrolled in the study, we were unable to obtain genotypes for 5-HTTLPR and/or rs 25531 for seven women (98.7\% call rate). We were also unable to obtain rs6311 genotypes for seven women (98.7\% call rate). Only one individual received neither a SLC6A4 or rs6311 genotype. Participants without genotype calls were not included in the analyses. We randomly selected $10 \%$ of the samples to genotype again, and had $99 \%$ consistency with the first genotype results for SLC6A4 and 100\% for rs6311; any sample that yielded a discrepancy between the initial genotyping result and that of the discrepancy test was run again and corrected in the dataset. Observed genotype frequencies are reported in Table 2 and are consistent with Hardy-Weinberg equilibrium (5-HTTLPR $\chi^{2}=.11$, rs25531 $\chi^{2}=.71, \mathrm{rs} 6311 \chi^{2}=.18$ ). Minor allele frequencies (5-HTTLPR S $=.44, \mathrm{rs} 25531 \mathrm{G}=$ .07 , rs6311 $\mathrm{A}=.40$ ) were similar to expectations for a primarily White sample (Haberstick et al. 2015).

\begin{tabular}{lccc}
\hline \multicolumn{3}{l}{ Table 2. Genotype frequencies for serotonin transporter and serotonin receptor 2A } \\
\hline Gene & Polymorphism & Genotype & Frequency (percent) \\
\hline SLC6A4 & 5-HTTLPR & L/L & $169(31.5 \%)$ \\
& & L/S & $260(48.4 \%)$ \\
& & S/S & $106(19.7 \%)$ \\
SLC6A4 & XL/S & $2(0.4 \%)$ \\
& rs25531 & A/A & $460(86.5 \%)$ \\
& & A/G & $68(12.8 \%)$ \\
HTR2A & G/G & $4(.8 \%)$ \\
& rs6311 & G/G & $196(36.8 \%)$ \\
& & G/A & $250(47 \%)$ \\
& & A/A & $86(16.2 \%)$ \\
\hline
\end{tabular}

\section{Genetic Moderation of Direct Paths}

All moderation hypotheses tested are shown with path coefficients in Figure 1. Genetic moderation of the effects of objectification on both body surveillance and body shame was found. Path A from objectification to body surveillance was moderated by serotonin transporter genotype $(b=-.29, S E=.06, p<.001 ; \beta=-.39)$, rs6311 genotype $(b=-.28, S E=.07, p$ $<.001, \beta=-.43)$, and their epistatic interaction $(b=.28, S E=.08, p=.001 ; \beta=.42)$. This association was significant only for women with the $\mathrm{L}^{\prime} / \mathrm{L}^{\prime}$ and $\mathrm{G} / \mathrm{G}$ genotypes $(b=.29, S E=$ $.05, p<.001)$ and not for women with the $\mathrm{L}^{\prime} / \mathrm{L}^{\prime}$ and $\mathrm{A} /$ _ genotypes $(b=.01, S E=.05, p=.87)$, women with the $\mathrm{S}^{\prime}{ }_{-}$and $\mathrm{G} / \mathrm{G}$ genotypes $(b=.01, S E=.04, p=.88)$, or women with the $\mathrm{S}^{\prime}{ }_{-}$ and $\mathrm{A} /$ _ genotypes $(b=.001, S E=.03, p=.96)$.

Despite a significant bivariate correlation of moderate magnitude between body surveillance and body shame (Table 1, $r=.50, p<.001)$, Path B was not significant $(b=.22, S E=.19$, $p=.22)$ nor was it moderated by any genotype variables when controlling for all the variables in the model (the interaction with $S L C 6 A 4$ genotype: $b=-.29, S E=.23, p=.21$; the interaction with rs6311 genotype: $b=-.13, S E=.26, p=.62$; the three-way interaction: $b=.39$, 
$S E=.30, p=.19)$. Thus, when controlling for objectification and the other covariates, body surveillance was not uniquely associated with body shame.

Path $C$ from body shame to disordered eating was significant $(b=4.11, S E=1.79, p<$ .001 ) and was not moderated by any of the genotype variables (interaction with SLC6A4 genotype: $b=-3.09, S E=2.15, p=.15$; interaction with rs6311 genotype: $b=-2.83, S E=2.36$, $p=.23$; three-way interaction: $b=4.42, S E=2.77, p=.18$ ). That is, the significant association between body shame and disordered eating did not vary as a function of genotype.

Path D, representing the unique association between objectification and body shame controlling for body surveillance, genotypes, and other covariates, was moderated by SLC6A4 genotype $(b=-.55, S E=.10, p<.001)$, rs6311 genotype $(b=-.55, S E=.11, p<.001)$, and their epistatic interaction $(b=.55, S E=.13, p<.001)$. The association between objectification and body shame was only significant for women with both the L'/L' genotype and $\mathrm{G} / \mathrm{G}$ genotype $(b=.56, S E=.09, p<.001)$. The association was not significant for women with the L'/L' genotype but carrying the A allele $(b=.01, S E=.07, p=.91)$, women with the $\mathrm{G} / \mathrm{G}$ genotype but carrying the $\mathrm{S}^{\prime}$ allele $(b=.004, S E=.05, p=.94)$, or women carrying both the $S^{\prime}$ allele and A allele $(b=.001, S E=.04, p=.98)$.

Path $\mathrm{E}$ from body surveillance to disordered eating (controlling for objectification, body shame, genotypes, and other covariates) was not significant $(b=-1.29, S E=2.3, p=.58)$ nor was it moderated by any genotype variables (interaction with $S L C 6 A 4$ genotype: $b=3.07$, $S E=2.61, p=.24$; interaction with rs6311 genotype: $b=2.07, S E=3.00, p=.49$; threeway interaction: $b=-4.36, S E=3.40, p=.20$ ).

Path F from objectification to disordered eating (controlling for body surveillance, body shame, genotypes, and other covariates) was not significant $(b=2.91, S E=2.16, p=.18)$ nor was it moderated by any genotype variables (interaction with SLC6A4 genotype: $b=.37$, $S E=2.41, p=.88$; interaction with rs6311 genotype: $b=-.64, S E=2.50, p=.80$; three-way interaction: $b=-1.29, S E=2.30, p=.58$ ).

To help illustrate further how the associations among objectification, body shame, body surveillance, and disordered eating differ among the different possible combinations of genotypes, bivariate correlations split by each possible combination of genotypes are provided in Table 3. When considering that only paths $\mathrm{A}$ and $\mathrm{D}$ were moderated by genotypes in the multivariate model, it is particularly useful to note that the association between objectification and body shame, as well as the association between objectification and body surveillance, is strongest for women with the $\mathrm{L}^{\prime} / \mathrm{L}^{\prime}$ genotype of SLC6A4 and the G/G genotype of rs25531. 
Table 3. Bivariate correlations for each combination of genotypes

\begin{tabular}{|c|c|c|c|c|c|c|c|c|c|c|c|}
\hline & \multicolumn{11}{|c|}{ 5-HTTLPR genotype } \\
\hline & & $\mathrm{L}^{\prime} / \mathrm{L}^{\prime}$ & & & & & $\mathrm{S}^{\prime} l_{-}$ & & & & \\
\hline \multirow[t]{12}{*}{ rs6311 genotype } & \multirow[t]{6}{*}{$\mathrm{G} / \mathrm{G}$} & \multicolumn{5}{|c|}{ 5-HTTLPR L'/L' and rs6311 G/G $(n=51,9.70 \%)$} & \multicolumn{5}{|c|}{ 5-HTTLPR S'/_ and rs6311 G/G ( $n=143,27.19 \%)$} \\
\hline & & & 1 & 2 & 3 & 4 & & 1 & 2 & 3 & 4 \\
\hline & & 1. Objectification & - & & & & 1. objectification & - & & & \\
\hline & & 2. Body shame & $.295^{*}$ & - & & & 2. body shame & $.195^{*}$ & - & & \\
\hline & & 3. Body surveillance & $.284^{*}$ & $.595^{* *}$ & - & & 3. body surveillance & .133 & $.437^{* *}$ & - & \\
\hline & & 4. Disordered eating & .241 & $.741^{* *}$ & $.414^{* *}$ & - & 4. disordered eating & $.282^{* *}$ & $.534^{* *}$ & $.377^{* *}$ & - \\
\hline & \multirow[t]{6}{*}{$\mathrm{A} /{ }_{-}$} & \multicolumn{5}{|c|}{ 5-HTTLPR L'/L' and rs6311 A/_ $(n=75,27.19 \%)$} & \multicolumn{5}{|c|}{ 5-HTTLPR S'/_ and rs6311 A/_ $(n=257,48.85 \%)$} \\
\hline & & & 1 & 2 & 3 & 4 & & 1 & 2 & 3 & 4 \\
\hline & & 1. Objectification & - & & & & 1. objectification & - & & & \\
\hline & & 2. Body shame & .188 & - & & & 2. body shame & .083 & - & & \\
\hline & & 3. Body surveillance & .179 & $.479^{* *}$ & - & & 3. body surveillance & .115 & $.525^{* *}$ & - & \\
\hline & & 4. Disordered eating & .106 & $.609^{* *}$ & $.388^{* *}$ & - & 4. disordered eating & .097 & $.630^{* *}$ & $.355^{* *}$ & - \\
\hline
\end{tabular}

\section{Genetic Moderation of Indirect Path}

Next, we estimated conditional indirect effects to determine whether there was evidence of mediation and for whom (i.e., under what combinations of genotypes). The indirect effect of objectification on disordered eating through body shame was only present for women with both the $\mathrm{L}^{\prime} / \mathrm{L}^{\prime}$ and $\mathrm{G} / \mathrm{G}$ genotype $(b=4.08,95 \% \mathrm{CI}[.56,10.61])$. The indirect effect was not present for women with the $\mathrm{L}^{\prime} / \mathrm{L}^{\prime}$ genotype but carrying the A allele $(b=.06$, $95 \% \mathrm{CI}[-.02, .30])$, women with the $\mathrm{G} / \mathrm{G}$ genotype but carrying the $\mathrm{S}^{\prime}$ allele $(b=.03,95 \% \mathrm{CI}$ $[-.03, .19])$, or women carrying both the $S^{\prime}$ allele and A allele $(b=.01,95 \% \mathrm{CI}[-.03, .09])$. We detected no other significant conditional indirect effects. The indirect effects through body surveillance are also reported in Table 4 , and as expected, they were not significant for any of the genotype groups (due to the lack of a direct paths from body surveillance to both body shame and eating problems).

\begin{tabular}{|c|c|c|c|c|c|c|c|}
\hline \multirow{2}{*}{$\begin{array}{l}\text { SERT } \\
\text { genotype }\end{array}$} & \multirow{2}{*}{$\begin{array}{c}\text { rs6311 } \\
\text { genotype }\end{array}$} & \multicolumn{2}{|c|}{$\begin{array}{l}\text { Objectification } \rightarrow \\
\text { body shame } \rightarrow \\
\text { disordered eating }\end{array}$} & \multicolumn{2}{|c|}{$\begin{array}{l}\text { Objectification } \rightarrow \\
\text { body surveillance } \rightarrow \\
\text { disordered eating }\end{array}$} & \multicolumn{2}{|c|}{$\begin{array}{l}\text { Objectification } \rightarrow \\
\text { body surveillance } \rightarrow \\
\text { body shame } \rightarrow \\
\text { disordered eating }\end{array}$} \\
\hline & & $b$ & $95 \% \mathrm{CI}$ & $b$ & $95 \% \mathrm{CI}$ & $b$ & $95 \% \mathrm{CI}$ \\
\hline \multirow[t]{2}{*}{$\mathrm{L}^{\prime} / \mathrm{L}^{\prime}$} & $\mathrm{G} / \mathrm{G}$ & 4.077 & {$[.556,10.614]^{\mathrm{a}}$} & -.833 & {$[-5.214,1.260]$} & 1.722 & {$[-.538,6.599]$} \\
\hline & $\mathrm{A} /{ }_{-}$ & .060 & {$[-.015, .295]$} & -.025 & {$[-.216, .059]$} & .698 & {$[-1.631,4.316]$} \\
\hline \multirow[t]{2}{*}{$S^{\prime} l_{-}$} & $\mathrm{G} / \mathrm{G}$ & .027 & {$[-.030, .191]$} & -.015 & {$[-.188, .024]$} & -.537 & {$[-2.608, .734]$} \\
\hline & $\mathrm{A} /{ }_{-}$ & .007 & {$[-.032, .087]$} & -.004 & {$[-.082, .028]$} & 1.463 & {$[-.059,3.583]$} \\
\hline
\end{tabular}

${ }^{a}$ A significant indirect effect from objectification to disordered eating was found through body shame for women with the $\mathrm{L}^{\prime} / \mathrm{L}^{\prime}$ genotype of the serotonin transporter variant and the G/G genotype of rs6311. 


\section{Discussion}

The present study integrated objectification theory and research on genetic variation in the serotonin system to examine the association between objectification experiences and disordered eating. This purpose is in line with recent calls from gender researchers to consider gene-environment interactions (Salk and Hyde 2012). The present study provides evidence that serotonin transporter genotypes, HTR2A (rs6311) genotypes, and their epistatic interaction are associated with individual differences in how sexual objectification experiences are associated with body surveillance, body shame, and disordered eating. The indirect effect of objectification on disordered eating via body shame is only present for women with both the L'/L' genotype of SLC6A4 and the G/G genotype of rs6311, when accounting for all other variables in the model (SLC6A4 genotypes, rs6311 genotypes, age, race/ethnicity, and BMI, as well as the genetic interactions with the covariates). Thus, we find that when considering many factors that contribute to disordered eating, experiences of objectification are associated with disordered eating through body shame for women with certain genotypes but not other genotypes.

Ours is the first known investigation of an interaction between experiences of objectification and genotypes, emphasizing the importance of considering both objectification and genetic factors in risk for disordered eating. The present study supported the well-established role of body shame in mediating the effect of objectification on disordered eating, while integrating genetics into the objectification theory framework. Interestingly, the association between body shame and body surveillance was no longer significant when controlling for the other variables in our model, so body surveillance did not play a mediating role, as would have been expected based on previous evidence (Kozee et al. 2007). We did find the expected bivariate correlation between body shame and body surveillance, so the lack of association in the multivariate model suggests that the variables are not uniquely associated after accounting for the other variables in the model. It appears that the negative self-conscious emotional response of body shame rather than chronically reflecting on how one looks through body surveillance may be a key mediator associating objectification experiences with disordered eating, at least when also accounting for genetic variation in the serotonin system. Therefore, the present study suggests that body shame is more important than body surveillance in explaining the mechanism of objectification's effect on disordered eating, after accounting for age, race/ethnicity, BMI, and genetic effects.

Although the identified interaction between objectification and genetic variation is novel, it is consistent with evidence that other individual differences (e.g., trait self-objectification) moderate the association between objectification experiences and body shame (Fredrickson et al. 1998). It is also consistent with evidence that other environmental stressors may interact with serotonin transporter genotype and rs6311 genotype (i.e., diathesis stress model or differential susceptibility hypothesis; Mellman et al. 2009; Sadeh et al. 2010). Interestingly, the gene-body surveillance and gene-body shame interactions were not significant, suggesting that L'/L' genotype of SLC6A4 and the G/G genotype of rs6311 may make women most responsive to direct social stressors (i.e., stressors in interactions with other people) rather than manifestations of social stressors, which may stem from both social 
stressors (exposure to objectification in interactions) but also other variables (exposure to objectification in media).

The epistatic interaction between SLC6A4 and rs6311 genotypes also corresponds with other evidence identifying an interaction between these variants, which showed highest impulsivity for people with the SLC6A4 L'/L' genotype and rs6311 G/G genotypes (Stoltenberg et al. 2012a, b). The higher impulsivity previously found for people with these genotypes also is consistent with our results because impulsivity plays a role in eating disorder risk (Lavender and Mitchell 2015). Although other studies have identified increased risk for anorexia nervosa for the $S^{\prime}$ allele of the serotonin transporter genotype (Calati et al. 2011) and the A allele of rs6311 (Enoch et al. 1998), ours is the first known study to identify a pathway that more specifically characterizes disordered eating risk for women with the L'/L' serotonin transporter genotype and the G/G rs6311 genotype, which further emphasizes the importance of context in considering genetic risk.

The context-dependent nature of genetic contributions to complex outcomes such as disordered eating can be very specific, so genetic effects may not be robust to even subtle changes in methodology and model specification, contributing to issues with replication in candidate-gene association studies (Dick et al. 2015; Duncan and Keller 2011). Although testing for moderation of all paths in the current model is theoretically justified (e.g., Fredrickson and Roberts 1997; see Moradi and Huang 2008, for review), and leading psychometricians advocate for including all theoretically meaningful paths in the model regardless of significance (Hayes 2013), we did a follow-up analysis removing nonsignificant genetic interactions from the model to see if the effects were robust to a simplification of the model (see the supplementary material).

When constraining the later paths $(\mathrm{B}, \mathrm{C}$, and $\mathrm{E})$ to be the same across genotype, the genetic moderation was no longer significant. Specifically, there was still evidence for the indirect effect of objectification on disordered eating via body shame, but this pathway did not vary as a function of genotype. This could be attributed to the fact that even subtle variation in specific paths as a function of moderators, even if moderation for certain paths does not reach statistical significance, can ultimately contribute to significant variation overall in indirect effects (Hayes 2013). Indeed, in the full model, we found that the indirect effect of objectification on disordered eating via body shame did vary as a function of genotype even though some of the interactions for specific paths (e.g., from body shame to disordered eating) did not reach statistical significance.

Although these preliminary effects must be interpreted with caution, our results are consistent with the notion that DNA is not destiny. Genetic variation in the serotonin system is often associated with eating disorders; yet, our results suggest that this genetic variation works in tandem with the gender-oppressive environment in which women live. Women with more frequent objectification experiences as well as certain serotonin transporter genotypes and rs6311 genotypes report higher disordered eating compared to women who have these genotypes and less frequent objectification experiences or to women with different genotypes. Genetics is a useful tool for understanding the development of eating disorders; however, the current investigation highlights the importance of also recognizing the role of discriminatory behaviors that women experience daily in patriarchal cultures. 
One of the major benefits of the genetic evidence provided is that it helps frame our speculations regarding the biological mechanisms underlying individual differences in responsiveness to social stress such as sexual objectification and how this could be connected to outcomes such as disordered eating. Reduced serotonergic neurotransmission is associated with disordered eating (Gauthier et al. 2014), so downregulation of the serotonin system may help explain how serotonin transporter genotype, serotonin receptor genotype, and objectification are associated with disordered eating via body shame. A higher density of serotonin transporters (conferred by the $\mathrm{L}^{\prime} / \mathrm{L}^{\prime}$ genotype) results in more reuptake of serotonin from the synapse and negative feedback of serotonin release (meaning there would be less subsequent serotonergic neurotransmission; Fuller and Wong 1977). Research shows the decreased serotonin associated with dietary restriction is attributed to increased responsiveness of negative feedback of serotonin (Haleem 2009). Thus, the increased negative feedback of serotonin release in women with the L'/L' genotype, in conjuncture with a reduced number of post-synaptic serotonin 2A receptors (which is likely in women with the G/G genotype; Polesskaya and Sokolov 2002, Turecki et al. 2000), may make women with these genotypes more vulnerable to the reduction in serotonin levels that result from stressors such as objectification (Moradi 2013) because their serotonergic neurotransmission may already be lower (Kennet et al. 1986). The use of SSRIs would inhibit the function of some of the increased number of serotonin transporters in women with the L'/L' genotype (Sahraian et al. 2013), perhaps helping to explain the utility of SSRIs in the treatment of eating disorders for women with this genotype. Serotonin receptor 2A agonists may have similarly beneficial effects, based on our findings and previous evidence that stress can act on serotonin 2A receptor functioning, which in turn can result in restricted eating and can be potentially treated with serotonin 2A receptor agonists (Compan et al. 2012).

\section{Limitations and Future Directions}

Although the cross-sectional nature of our study does not provide evidence for the temporal order of the variables, we relied on a model derived from objectification theory (Fredrickson and Roberts 1997) that has received substantial empirical support (Calogero and Pina 2011; Moradi and Huang 2008; Roberts et al. 2018). Future longitudinal studies that ask about recent experiences of objectification could provide direct support for the temporal precedence of objectification preceding changes in body shame and subsequent disordered eating and offer a more individual and developmental approach (Fausto-Sterling 2012). Further, it is notable that the model explained only $4.3 \%$ of the variance in body surveillance in contrast to $48.4 \%$ of the variance in body shame and $38.2 \%$ of the variance in disordered eating.

Additionally, independent replication is vital for verifying results, particularly in genetic studies with small effect sizes. Only $27 \%$ of replication studies confirm previous genebyenvironment interactions (Duncan and Keller 2011). We used a sensitivity power analysis, which is a post-hoc analysis that estimates the minimum effect size that could be detected at a given power level for the obtained sample size. This is customary when the sample size is predetermined by study constraints (e.g., data have already been collected for the study; Faul et al. 2007). The sensitivity power analysis suggests that we had adequate 
power $(.80)$ to detect very small effect sizes $\left(f^{2}>.015\right)$ for each path; however, our sample size was smaller than recommendations for candidate-gene studies (Duncan and Keller 2011), so future studies should aim for larger samples. Model convergence issues when attempting to add parameters to the model to control for additional environment $\times$ covariate interaction terms (as recommended by Dick et al. 2015) also may evidence sample size limitations in our study. The environment $\times$ covariate terms were ultimately omitted from the model for the sake of prioritizing more theoretically relevant paths and limiting model complexity for model convergence.

Despite these limitations, our results represent a first step in incorporating genetic variables into objectification theory. Replicability of the identified genetic moderation seems feasible because the concept of $\mathrm{L}^{\prime} / \mathrm{L}^{\prime}$ and $\mathrm{G} / \mathrm{G}$ genotypes conferring higher sensitivity to social stressors is consistent with prior evidence (Lee and Lin 2010; Mellman et al. 2009; Sadeh et al. 2010). Our study did not test general stress to investigate how serotonergic genetic variation potentially predisposing women to more general responsivity to stress could contribute to disordered eating; further research should elucidate how objectification may be similar to and unique from other sources of environmental, social, and discriminatory stress and whether genetic variation interacts differently across various stressors.

Although objectification often occurs interpersonally, it is important to remember that it occurs in a larger cultural context in which women are objectified to a much greater degree than men are, and with more adverse consequences than men (Moradi and Huang 2008; Roberts et al. 2018). Thus, future research should disentangle the degree to which these effects are driven by social stressors in general, but also social stressors that disproportionately affect women in a society in which such sexist stressors serve to create, justify, and maintain power and status differences between men and women (Moradi 2013). Questions regarding how people of varying gender identities and sexual orientations may be differentially impacted were also outside the scope of our study because the current sample was self-selected participants who identified themselves as women (a potentially heterogeneous population known to be disproportionately targeted by objectification). The generalizability of our results may be limited by the fact that it was conducted with a convenience sample. It may be that additional studies with greater diversity in age, race, ethnicity, gender, and sexual orientation could enrich our understanding of how intersections of identity contribute to different responses to objectification (Etaugh and Worell 2012).

Our study reports a stronger path from objectification to disordered eating through body shame for women with the L'/L' genotype of SLC6A4. Some factors (e.g., childhood trauma), however, are better risk factors for disordered eating for women with the $S^{\prime} /$ genotype (Stoltenberg et al. 2012a, b), so it stands to reason there may be differences between these social stressors. Individuals homozygous for the $L$ allele are particularly sensitive to the effects of tryptophan depletion (used to decrease central nervous system serotonin) on learning associations with rewards and punishments. Objectification is a form of sexism that may (at least on the surface) appear to reward women who have bodies that fit cultural ideals of feminine attractiveness while punishing women who violate these cultural ideals. Women who are thin, well-proportioned, young, and White, for example, may experience complimentary gazes and related commentary whereas women who are 
overweight, older, or from racial/ethnic minorities who violate Western standards of attractiveness may experience critical commentary and rejection behaviors. Unfortunately, like other forms of sexism (e.g., ambivalent sexism, Glick and Fiske 1996), both complimentary and critical forms of objectification contribute to self-objectification (Calogero et al. 2009), which may make women particularly sensitive to future instances of sexual objectification. Women with the $\mathrm{L}^{\prime} / \mathrm{L}^{\prime}$ genotype might also be particularly sensitive to the serotonin reduction from objectification (Blair et al. 2008). Further specification of which eating disorder symptoms are associated with which combinations of genotypes and environmental factors may help to explain individual differences in disordered eating in women with different genetic profiles. Longitudinal studies could provide clearer indications regarding changes in disordered eating following objectification.

\section{Practice Implications}

The results of the present study, in conjunction with previous findings, urge a shift in the way disordered eating, genetics, and experiences are discussed in therapeutic contexts, educational contexts, media, and generally. Eating disorder prevention educational efforts rely on empowerment, body positivity, and rejection of the thin ideal in women (Breithaupt et al. 2017). The present work suggests that reducing women's experiences with objectification in the first place should feature prominently into these efforts. These prevention efforts could focus on getting men to objectify women less, given that men objectify women to a greater degree than women objectify women (Gervais et al. 2017).

Furthermore, understanding how objectification impacts women differentially depending on genetics may have other important therapeutic implications. For women already struggling with eating disorders, further understanding the etiology of these disorders may help reduce the sense of stigma (Crisp et al. 2000). By acknowledging the roles of both societal and biological forces in eating disorders, women may feel less personal blame for their illness, reducing the guilt and shame that can undermine treatment efforts. Considering the present study, practitioners and educators are advised to acknowledge the complexity of the factors that may contribute to disordered eating.

Furthermore, understanding the factors involved in the development of an eating disorder might help guide more individualized treatment. Precision treatment (i.e., personalized medicine) suggests that researchers and practitioners find the most efficacious and least harmful pharmaceutical treatments for individuals by focusing "below the skin" on metabolism, epigenetics, and genetics as a guide (Gillman and Hammond 2016), and this has been an important focus of eating disorder treatment (Shafran 2013). Different eating disorder medications targeting the serotonin transporter and serotonin receptor 2A may be differentially effective depending on the specific genotypes (Steiger et al. 2008). At the same time, precision prevention involves tailoring behavioral interventions to people's characteristics focusing "above the skin" on helping individuals overcome psychosocial barriers, emphasizing achievable goals, or adapting to people's economic and cultural circumstances.

The present results suggest that medications focusing on genetics alone are unlikely to eliminate eating disorders and that addressing the role of objectification experiences will 
be critical for providing tailored and effective prevention and treatment of eating disorders. Although the current study does not yield specific recommended interventions, it emphasizes the importance of considering how medications that alter serotonergic functioning and therapeutic methods addressing objectification experiences may interact and differently impact individuals. The results of the present study identify both sociocultural and biological avenues to target with individualized treatment and emphasize the need for a holistic approach to individualized treatment. For example, if a woman presents problematic eating attitudes to a physician or mental health practitioner, the findings from our paper suggest that it would be important to consider both biological (genetic risk) and environmental factors (objectification) that may contribute to this issue.

\section{Conclusion}

Evidence that certain genetic variation may increase risk for disordered eating is unsatisfactory without considering the contribution of the complex social pressures and experiences of living in a culture in which women are chronically oppressed through objectification. Indeed, bivariate genetic associations and multivariate genetic main effects were not significant in the present work. Accounting for both genetic and environment influences was necessary to explain disordered eating in our sample. Integrating genetic moderation into models of disordered eating based on objectification theory complements our consideration of the unique social pressures and experiences women face. This perspective suggests that although some women who are exposed to high levels of objectification may not exhibit increased disordered eating, genetic variation in the serotonin system may help account for why objectification is particularly impactful for other women.

The current study advances the integration of feminist psychology and genetics research by incorporating a feminist theory (objectification theory) that has received strong empirical support (Moradi and Huang 2008; Roberts et al. 2018) with genetics research on the serotonin systems. The results emphasize the prevalence of disordered eating in women as a likely result of a dynamic system of common genetic variation and social stressors, such as objectification that disproportionately impacts women (Moradi 2013), thus supporting other researchers' calls for understanding gender differences as dynamic systems (Fausto-Sterling 2012). Our study is an important first step to help account for the complexity of the relations between different genetic variants in the serotonin system and objectification in risk for eating disorders. Thus, it contributes empirical evidence for a nondeterministic perspective regarding the role of genetic variation in individual differences in risk for disordered eating in women.

Acknowledgments - This project was funded in part by a grant from the Substance Abuse and Violence Initiative from the Office of Research at the University of Nebraska awarded to S.F.S and S.J.G.

Ethical Approval - Our study was approved by the University of Nebraska-Lincoln IRB; all participants were treated with respect and conformity with APA guidelines for ethical treatment, and they provided signed informed consent.

Conflict of Interest - None of the authors have conflicts of interest. 


\section{References}

Ackard, D. M., Croll, J. K., \& Kearney-Cooke, A. (2002). Dieting frequency among college females: Association with disordered eating, body image, and related psychological problems. Journal of Psychosomatic Research, 52, 129-136. https://doi.org/10.1016/S0022-3999(01)00269-0.

Ando, T., Komaki, G., Karibe, M., Kawamura, N., Hara, S., Takii, M., . . Ohba, M. (2001). 5-HT2A promoter polymorphism is not associated with anorexia nervosa in Japanese patients. Psychiatric Genetics, 11, 157-160. https://doi.org/10.1097/00041444-200109000-00008.

Barrett, P. (2007). Structural equation modelling: Adjudging model fit. Personality and Individual Differences, 42(5), 815-824. https://doi.org/10.1016/j.paid.2006.09.018.

Bartky, S. L. (1970). Femininity and domination: Studies in the phenomenology of oppression. New York: Routledge. https://doi.org/10.4324/9780203825259.

Bentler, P. M. (1990). Comparative fit indexes in structural models. Psychological Bulletin, 107, 238-246. https://doi.org/10.1037/0033-2909.107.2.238.

Black, E. (2003). War against the weak: Eugenics and America's campaign to create a master race (Vol. 91, p. 671). New York: ThunderMount Press. https://doi.org/10.2307/3660797.

Blair, K. S., Finger, E., Marsh, A. A., Morton, J., Mondillo, K., Buzas, B. Blair, R. J. R. (2008). The role of 5-HTTLPR in choosing the lesser of two evils, the better of two goods: Examining the impact of 5-HTTLPR genotype and tryptophan depletion in object choice. Psychopharmacology, 196, 2938. https://doi.org/10.1007/s00213-007-0920-y.

Blundell, J. E., Lawton, C. L., \& Halford, J. C. (1995). Serotonin, eating behavior, and fat intake. Obesity, 3(S4), 471S-476S. https://doi.org/10.1002/j.1550-8528.1995.tb00214.x.

Breithaupt, L., Eickman, L., Byrne, C. E., \& Fischer, S. (2017). Enhancing empowerment in eating disorder prevention: Another examination of the REbeL peer education model. Eating Behaviors, 25, 38-41. https://doi.org/10.1016/j.eatbeh.2016.05.003.

Brown, T. A. (2015). Confirmatory factor analysis for applied research. New York: Guilford Publications. http://www.kharazmi-statistics.ir/Uploads/Public/book/Methodology\%20in\%20the\%20Social\%20 Sciences.pdf.

Browne, M. W., \& Cudeck, R. (1992). Alternative ways of assessing model fit. Sociological Methods $\mathcal{E}$ Research, 21, 230-258. https://doi.org/10.1177/0049124192021002005.

Bruce, K. R., Steiger, H., Joober, R., Kin, N. M. K., Israel, M., \& Young, S. N. (2005). Association of the promoter polymorphism -1438G/a of the 5-HT2A receptor gene with behavioral impulsiveness and serotonin function in women with bulimia nervosa. American Journal of Medical Genetics Part B: Neuropsychiatric Genetics, 137, 40-44. https://doi.org/10.1002/ajmg.b.30205.

Calati, R., De Ronchi, D., Bellini, M., \& Serretti, A. (2011). The 5HTTLPR polymorphism and eating disorders: A meta-analysis. International Journal of Eating Disorders, 44, 191-199. https://doi.org/ 10.1002/eat.20811.

Calogero, R. M. (2004). A test of objectification theory: The effect of the male gaze on appearance concerns in college women. Psychology of Women Quarterly, 28, 16-21. https://doi.org/10.1111/ j.1471-6402.2004.00118.x.

Calogero, R. M., \& Pina, A. (2011). Body guilt: Preliminary evidence for a further subjective experience of self-objectification. Psychology of Women Quarterly, 35, 428-440. https://doi.org/10.1177/ 0361684311408564.

Calogero, R. M., Herbozo, S., \& Thompson, J. K. (2009). Complimentary weightism: The potential costs of appearance-related commentary for women's self-objectification. Psychology of Women Quarterly, 33, 120-132. https://doi.org/10.1111/j.1471-6402.2008.01479.x. 
Calogero, R. M., Pina, A., Park, L. E., \& Rahemtulla, Z. (2010). Objectification theory predicts college women's attitudes toward cosmetic surgery. Sex Roles, 63, 32-41. https://doi.org/10.1007/s11199010-9759-5.

Cashel, M. L., Cunningham, D., Landeros, C., Cokley, K. O., \& Muhammad, G. (2003). Sociocultural attitudes and symptoms of bulimia: Evaluating the SATAQ with diverse college groups. Journal of Counseling Psychology, 50, 287-296. https://doi.org/10.1037/0022-0167.50.3.287.

Castellini, G., Franzago, M., Bagnoli, S., Lelli, L., Balsamo, M., Mancini, M., . . Stanghellini, G. (2017). Fat mass and obesity-associated gene (FTO) is associated to eating disorders susceptibility and moderates the expression of psychopathological traits. PLoS One, 12(3), 1-14. https://doi.org/ 10.1371/journal.pone.0173560.

Compan, V., Laurent, L., Jean, A., Macary, C., Bockaert, J., \& Dumuis, A. (2012). Serotonin signaling in eating disorders. WIREs Membr Transp Signal, 1, 715-729. https://doi.org/10.1002/wmts.45.

Crisp, A. H., Gelder, M. G., Rix, S., Meltzer, H. I., \& Rowlands, O. J. (2000). Stigmatisation of people with mental illnesses. The British Journal of Psychiatry, 177, 4-7. https://doi.org/10.1192/bjp.177.1.4.

Davidson, M. M., Robins, K., Scheel, M., Sherd, L., \& Gervais, S. J. (2016). The mediating role of perceived safety on street harassment and anxiety. Psychology of Violence, 6(4), 553-561. https://doi .org/10.1037/a0039970.

Devlin, B., Bacanu, S. A., Klump, K. L., Bulik, C. M., Fichter, M. M., Halmi, K. A., . . Kaye, W. H. (2002). Linkage analysis of anorexia nervosa incorporating behavioral covariates. Human Molecular Genetics, 11, 689-696. https://doi.org/10.1093/hmg/11.6.689.

Dick, D. M., Agrawal, A., Keller, M. C., Adkins, A., Aliev, F., Monroe, S., . . Sher, K. J. (2015). Candidate gene-environment interaction research: Reflections and recommendations. Perspectives on Psychological Science, 10, 37-59. https://doi.org/10.1177/1745691614556682.

Donnelly, L. C., \& Calogero, R. M. (2017). The role of stranger harassment experiences in college women's perceived possibility of gender crimes happening to them. Journal of Applied Social Psychology, 48, 1-9. https://doi.org/10.1111/jasp.12497.

Duncan, L., \& Keller, M. C. (2011). A critical review of the first ten years of measured gene-byenvironment interaction research in psychiatry. American Journal of Psychiatry, 168, 1041-1049. https://doi.org/10.1176/appi.ajp.2011.11020191.

Enoch, M. A., Kaye, W. H., Rotondo, A., Greenberg, B. D., Murphy, D. L., \& Goldman, D. (1998). 5-HT 2A promoter polymorphism -1438G/a, anorexia nervosa, and obsessive-compulsive disorder. The Lancet, 351, 1785-1786. https://doi.org/10.1016/S0140-6736(05)78746-8.

Enoch, M. A., Goldman, D., Barnett, R., Sher, L., Mazzanti, C. M., \& Rosenthal, N. E. (1999). Association between seasonal affective disorder and the 5-HT 2 a promoter polymorphism, 1438 G/a. Molecular Psychiatry, 4, 89-92. https://doi.org/10.1038/sj.mp.4000439.

Etaugh, C., \& Worell, J. (2012). Contemporary feminism for gender researchers: Not just “our bodies, our cells." Psychology of Women Quarterly, 36, 419-422. https://doi.org/10.1177/0361684312461905.

Fairchild, K., \& Rudman, L. A. (2008). Everyday stranger harassment and women's objectification. Social Justice Research, 21, 338-357. https://doi.org/10.1007/s11211-008-0073-0.

Falkenberg, V. R., Gurbaxani, B. M., Unger, E. R., \& Rajeevan, M. S. (2011). Functional genomics of serotonin receptor 2A (HTR2A): Interaction of polymorphism, methylation, expression and disease association. Neuromolecular Medicine, 13, 66-76. https://doi.org/10.1007/s12017-010-8138-2.

Faul, F., Erdfelder, E., Lang, A.-G., \& Buchner, A. (2007). G* power 3: A flexible statistical power analysis program for the social, behavioral, and biomedical sciences. Behavior Research Methods, 39, 175-191. 
Fausto-Sterling, A. (2012). Not your grandma's genetics: Some theoretical notes. Psychology of Women Quarterly, 36, 411-418. https://doi.org/10.1177/0361684312462016.

Favaro, A. (2013). Brain development and neurocircuit modeling are the interface between genetic/ environmental risk factors and eating disorders. A commentary on Keel \& Forney and Friederich et al. International Journal of Eating Disorders, 46, 443-446. https://doi.org/10.1002/eat.22131.

Fredrickson, B. L., \& Roberts, T. A. (1997). Objectification theory. Psychology of Women Quarterly, 21, 173-206. https://doi.org/10.1111/j.1471-6402.1997.tb00108.x.

Fredrickson, B. L., Roberts, T. A., Noll, S. M., Quinn, D. M., \& Twenge, J. M. (1998). That swimsuit becomes you: Sex differences in self-objectification, restrained eating, and math performance. Journal of Personality and Social Psychology, 75, 269-284. https://doi.org/10.1037/0022-3514.75.1.269.

Fuller, R. W., \& Wong, D. T. (1977). Inhibition of serotonin reuptake. Federation Proceedings, 36, $2154-$ 2158.

Garner, D. M., Olmsted, M. P., Bohr, Y., \& Garfinkel, P. E. (1982). The Eating Attitudes Test: Psychometric features and clinical correlates. Psychological Medicine, 12, 871-878. https://doi.org/10.1017/ S0033291700049163.

Gauthier, C., Hassler, C., Mattar, L., Launay, J. M., Callebert, J., Steiger, H., . . Lang, F. (2014). Symptoms of depression and anxiety in anorexia nervosa: Links with plasma tryptophan and serotonin metabolism. Psychoneuroendocrinology, 39, 170-178. https://doi.org/10.1016/j.psyneuen.2013.09.009.

Gervais, S. J., Davidson, M. M., Styck, K., Canivez, G., \& DiLillo, D. K. (2017). The development and psychometric properties of the Interpersonal Sexual Objectification Scale-Perpetration Version. Psychology of Violence, 8(5), 546-559. https://doi.org/10.1037/vio0000148.

Gillman, M. W., \& Hammond, R. A. (2016). Precision treatment and precision prevention: Integrating "below and above the skin." JAMA Pediatrics, 170, 9-10. https://doi.org/10.1001/jamapediatrics.2015.2786.

Glick, P., \& Fiske, S. T. (1996). The Ambivalent Sexism Inventory: Differentiating hostile and benevolent sexism. Journal of Personality and Social Psychology, 70(3), 491-512. https://doi.org/10.1037/ 0022-3514.70.3.491.

Griffiths, R. A., Mallia-Blanco, R., Boesenberg, E., Ellis, C., Fischer, K., Taylor, M., \& Wyndham, J. (2000). Restrained eating and sociocultural attitudes to appearance and general dissatisfaction. European Eating Disorders Review, 8, 394-402. https://doi.org/10.1002/1099-0968(200010)8:5<394::AIDERV358>3.0.CO;2-B.

Grippo, K. P., \& Hill, M. S. (2008). Self-objectification, habitual body monitoring, and body dissatisfaction in older European American women: Exploring age and feminism as moderators. Body Image, 5(2), 173-182. https://doi.org/10.1016/j.bodyim.2007.11.003.

Gyurak, A., Haase, C. M., Sze, J., Goodkind, M. S., Coppola, G., Lane, J., . . Levenson, R. W. (2013). The effect of the serotonin transporter polymorphism (5-HTTLPR) on empathic and self-conscious emotional reactivity. Emotion, 13, 25-35. https://doi.org/10.1037/a0029616.

Haberstick, B. C., Smolen, A., Williams, R. B., Bishop, G. D., Foshee, V. A., Thornberry, T. P., . . Frajzyngier, Z. (2015). Population frequencies of the 5HTTLPR in six ethnicially diverse samples from North America, Southeast Asia, and Africa. Behavior Genetics, 45, 255-261. https://doi.org/ 10.1007/s10519-014-9703-5.

Haleem, D. J. (2009). Exaggerated feedback control decreases brain serotonin concentration and elicits hyperactivity in a rat model of dietrestriction-induced anorexia nervosa. Appetite, 52, 44-50. https://doi.org/10.1016/j.appet.2008.07.009. 
Hayduk, L., Cummings, G., Boadu, K., Pazderka-Robinson, H., \& Boulianne, S. (2007). Testing! Testing! One, two, three - Testing the theory in structural equation models! Personality and Individual Differences, 42, 841-850. https://doi.org/10.1016/j.paid.2006.10.001.

Hayes, A. F. (2013). Introduction to mediation, moderation, and conditional process analysis: A regressionbased approach. New York: The Guilford Press.

Heinberg, L. J., Thompson, J. K., \& Stormer, S. (1995). Development and validation of the Sociocultural Attitudes Towards Appearance Questionnaire. International Journal of Eating Disorders, 17, 81-89. https://doi.org/10.1002/1098-108X(199501)17:1<81::AID-EAT2260170111>3.0.CO;2-Y.

Hinney, A., \& Volckmar, A. L. (2013). Genetics of eating disorders. Current Psychiatry Reports, 15, 423. https://doi.org/10.1007/s11920-013-0423-y.

Hu, X., Oroszi, G., Chun, J., Smith, T. L., Goldman, D., \& Schuckit, M. A. (2005). An expanded evaluation of the relationship of four alleles to the level of response to alcohol and the alcoholism risk. Alcoholism: Clinical and Experimental Research, 29, 8-16. https://doi.org/10.1097/01.ALC.0000150008 .68473.62.

Josephs, R. A., Telch, M. J., Hixon, J. G., Evans, J. J., Lee, H., Knopik, V. S., . . Beevers, C. G. (2012). Genetic and hormonal sensitivity to threat: Testing a serotonin transporter genotype $\times$ testosterone interaction. Psychoneuroendocrinology, 37, 752-761. https://doi.org/10.1016/j.psyneuen.2011 .09 .006 .

Kaufman, J., Yang, B. Z., Douglas-Palumberi, H., Grasso, D., Lipschitz, D., Houshyar, S., .. Gelernter, J. (2006). Brain-derived neurotrophicfactor-5-HTTLPR gene interactions and environmental modifiers of depression in children. Biological Psychiatry, 59, 673-680. https://doi.org/10.1016/j.biopsych.2005.10.026.

Kaye, W. H., Barbarich, N. C., Putnam, K., Gendall, K. A., Fernstrom, J., Fernstrom, M., . . Kishore, A. (2003). Anxiolytic effects of acute tryptophan depletion in anorexia nervosa. International Journal of Eating Disorders, 33, 257-267. https://doi.org/10.1002/eat.10135.

Kennet, G. A., Chaouloff, F., Marcou, M., \& Curzon, G. (1986). Female rats are more vulnerable than males in an animal model of depression: The possible role of serotonin. Brain Research, 382, 416-421. https://doi.org/10.1016/0006-8993(86)91355-7.

Kozee, H. B., Tylka, T. L., Augustus-Horvath, C. L., \& Denchik, A. (2007). Development and psychometric evaluation of the Interpersonal Sexual Objectification Scale. Psychology of Women Quarterly, 31, 176-189. https://doi.org/10.1111/j.1471-6402.2007.00351.x.

Lavender, J. M., \& Mitchell, J. E. (2015). Eating disorders and their relationship to impulsivity. Current Treatment Options in Psychiatry, 2, 394-401. https://doi.org/10.1007/s40501-015-0061-6.

Lee, Y., \& Lin, P. Y. (2010). Association between serotonin transporter gene polymorphism and eating disorders: A meta-analytic study. International Journal of Eating Disorders, 43, 498-504. https://doi .org/10.1002/eat.20732.

Leibowitz, S. F., \& Alexander, J. T. (1998). Hypothalamic serotonin in control of eating behavior, meal size, and body weight. Biological Psychiatry, 44, 851-864. https://doi.org/10.1016/S0006-3223(98) 00186-3.

Lesch, K. P., Bengel, D., Heils, A., Sabol, S. Z., Greenberg, B. D., Petri, P., . . Murphy, D. L. (1996). Association of anxiety-related traits with a polymorphism in the serotonin transporter gene regulatory region. Science, 274, 1527-1531. https://doi.org/10.1126/science.274.5292.1527.

Liss, M., \& Erchull, M. J. (2015). Not hating what you see: Self-compassion may protect against negative mental health variables connected to self-objectification in college women. Body Image, 14, 5-12. https://doi.org/10.1016/j.bodyim.2015.02.006. 
Luce, K. H., Crowther, J. H., \& Pole, M. (2008). Eating Disorder Examination Questionnaire (EDE-Q): Norms for undergraduate women. International Journal of Eating Disorders, 41, 273-276. https://doi.org/ 10.1002/eat.20504.

MacCallum, R. C., Browne, M. W., \& Sugawara, H. M. (1996). Power analysis and determination of sample size for covariance structure modeling. Psychological Methods, 1, 130-149. https://doi.org/ 10.1037/1082-989X.1.2.130.

Maïano, C., Morin, A. J., Lanfranchi, M. C., \& Therme, P. (2013). The Eating Attitudes Test-26 revisited using exploratory structural equation modeling. Journal of Abnormal Child Psychology, 41, 775-788. https://doi.org/10.1007/s10802-013-9718-z.

Martásková, D., Slachtova, L., Kemlink, D., Záhoráková, D., \& Papezova, H. (2009). Polymorphisms in serotonin-related genes in anorexia nervosa. The first study in Czech population and metaanalyses with previously performed studies. Folia Biologica, 55, 192. https://fb.cuni.cz/Data/files/ folia_biologica/volume_55_2009_5/fb2009A0030.pdf.

McKinley, N. M., \& Hyde, J. S. (1996). The Objectified Body Consciousness Scale: Development and validation. Psychology of Women Quarterly, 20, 181-215. https://doi.org/10.1111/j.14716402.1996.tb00467.x.

Mellman, T. A., Alim, T., Brown, D. D., Gorodetsky, E., Buzas, B., Lawson, W. B., ... Charney, D. S. (2009). Serotonin polymorphisms and posttraumatic stress disorder in a trauma exposed African American population. Depression and Anxiety, 26, 993-997. https://doi.org/10.1002/da.20627.

Mitchell, J. E., Roerig, J., \& Steffen, K. (2013). Biological therapies for eating disorders. International Journal of Eating Disorders, 46, 470-477. https://doi.org/10.1002/eat.22104.

Moffitt, L. B., \& Szymanski, D. M. (2011). Experiencing sexually objectifying environments: A qualitative study. The Counseling Psychologist, 39(1), 67-106. https://doi.org/10.1177/0011000010364551.

Molnar, E., Lazary, J., Benko, A., Gonda, X., Pap, D., Mekli, K., . . Bagdy, G. (2010). Seasonality and winter-type seasonal depression are associated with the rs731779 polymorphism of the serotonin2A receptor gene. European Neuropsychopharmacology, 20, 655-662. https://doi.org/10.1016/j .euroneuro.2010.04.009.

Moradi, B. (2013). Discrimination, objectification, and dehumanization: Toward a pantheoretical framework. In S. J. Gervais (Ed.), Objectification and (De)humanization: 60th Nebraska symposium on motivation (pp. 153-181). New York: Springer. https://doi.org/10.1007/978-1-4614-6959-9_7.

Moradi, B., \& Huang, Y. P. (2008). Objectification theory and psychology of women: A decade of advances and future directions. Psychology of Women Quarterly, 32, 377-398. https://doi.org/10.1111/ j.1471-6402.2008.00452.x.

Moradi, B., Dirks, D., \& Matteson, A. V. (2005). Roles of sexual objectification experiences and internalization of standards of beauty in eating disorder symptomatology: A test and extension of objectification theory. Journal of Counseling Psychology, 52, 420-428. https://doi.org/10.1037/00220167.52.3.420.

Munn-Chernoff, M. A., McQueen, M. B., Stetler, G. L., Haberstick, B. C., Rhee, S. H., Sobik, L. E., . . Stallings, M. C. (2012). Examining associations between disordered eating and serotonin transporter gene polymorphisms. International Journal of Eating Disorders, 45, 556-561. https://doi.org/10.1002/ eat.22001.

Muthén, B. (2011). Applications of causally defined direct and indirect effects in mediation analysis using SEM in Mplus. Unpublished manuscript. https://pdfs.semanticscholar.org/776d/2df784e67ab691 bbffc280d3f4a480740300.pdf. 
Muthén, L., \& Muthén, B. (2010). Mplus user's guide. Sixth edition. Los Angeles: Author. Los Angeles, CA: Muthen \& Muthen. https://www.statmodel.com/download/usersguide/Mplus\%20Users\%20 Guide\%20v6.pdf.

Nisoli, E., Brunani, A., Borgomainerio, E., Tonello, C., Dioni, L., Briscini, L., .. Carruba, M. O. (2007). D2 dopamine receptor (DRD2) gene Taq1A polymorphism and the eating-related psychological traits in eating disorders (anorexia nervosa and bulimia) and obesity. Eating and Weight Disorders, 12, 91-96. https://doi.org/10.1007/BF03327583.

Noll, S. M., \& Fredrickson, B. L. (1998). A mediational model linking self-objectification, body shame, and disordered eating. Psychology of Women Quarterly, 22, 623-636. https://doi.org/10.1111/j.14716402.1998.tb00181.x.

Nussbaum, M. (1995). Objectification. Philosophy and Public Affairs, 24, 249-291. https://doi.org/10.1111/ j.1088-4963.1995.tb00032.x.

Ocker, L. B., Lam, E. T., Jensen, B. E., \& Zhang, J. J. (2007). Psychometric properties of the Eating Attitudes Test. Measurement in Physical Education and Exercise Science, 11, 25-48. https://doi.org/ 10.1080/10913670709337010.

Polesskaya, O. O., \& Sokolov, B. P. (2002). Differential expression of the " $\mathrm{C}$ " and " $\mathrm{T}$ " alleles of the 5-HT2A receptor gene in the temporal cortex of normal individuals and schizophrenics. Journal of Neuroscience Research, 67, 812-822. https://doi.org/10.1002/jnr.10173.

Ricca, V., Nacmias, B., Cellini, E., Di Bernardo, M., Rotella, C. M., \& Sorbi, S. (2002). 5-HT 2A receptor gene polymorphism and eating disorders. Neuroscience Letters, 323, 105-108. https://doi.org/10.1016/ S0304-3940(02)00088-5.

Roberts, T. A., Calogero, R., \& Gervais, S. J. (2018). Objectification theory: Continuing contributions to feminist psychology. In C. B. Travis \& J. W. White (Eds.), APA handbook of the psychology of women (pp. 249-272). Washington, DC: American Psychological Association. https://doi.org/10 .1037/0000059-013.

Rybakowski, F., Slopien, A., Dmitrzak-Weglarz, M., Czerski, P., Rajewski, A., \& Hauser, J. (2006). The 5-HT2A-1438 a/G and 5HTTLPR polymorphisms and personality dimensions in adolescent anorexia nervosa: Association study. Neuropsychobiology, 53, 33-39. https://doi.org/10.1159/ 000090701.

Sadeh, N., Javdani, S., Jackson, J. J., Reynolds, E. K., Potenza, M. N., Gelernter, J., . . Verona, E. (2010). Serotonin transporter gene associations with psychopathic traits in youth vary as a function of socioeconomic resources. Journal of Abnormal Psychology, 119, 604-609. https://doi.org/10.1037/ a0019709.

Sahraian, S., Babashams, M., Reza-Soltani, P., Najmabadi, H., Kahrizi, K., \& Gorgani, S. H. (2013). Serotonin transporter polymorphism (5-HTTLPR) and citalopram effectiveness in Iranian patients with major depressive disorder. Iranian Journal of Psychiatry, 8, 86-91. https://www.ncbi .nlm.nih.gov/pmc/articles/PMC3796299/.

Salk, R., \& Hyde, J. S. (2012). Contemporary genetics for gender researchers: Not your grandma's genetics anymore. Psychology of Women Quarterly, 36, 395-411. https://doi.org/10.1177/036168431 2461774.

Shafran, R. (2013). Promises, progress, and pathos: Commentary on "Treatment and Prevention" papers by Stice \& Becker, Hay, and Mitchell, Roenig \& Steffan. International Journal of Eating Disorders, 46, 486-488. https://doi.org/10.1002/eat.22118.

Smith, R. M., Papp, A. C., Webb, A., Ruble, C. L., Munsie, L. M., Nisenbaum, L. K., . . Sadee, W. (2013). Multiple regulatory variants modulate expression of 5-hydroxytryptamine $2 \mathrm{~A}$ receptors in human cortex. Biological Psychiatry, 73, 546-554. https://doi.org/10.1016/j.biopsych.2012.09.028. 
Steiger, H., Joober, R., Gauvin, L., Bruce, K. R., Richardson, J., Israel, M., . . Groleau, P. (2008). Serotoninsystem polymorphisms (5HTTLPR and -1438G/ a) and responses of patients with bulimic syndromes to multimodal treatments. Journal of Clinical Psychiatry, 69, 1565-1571. https://doi.org/10.4088/ JCP.v69n1006.

Stoltenberg, S. F., Anderson, C., Nag, P., \& Anagnopoulos, C. (2012a). Association between the serotonin transporter genotype and disordered eating is moderated by the experience of childhood trauma in women. International Journal of Eating Disorders, 45, 492-500. https://doi.org/10.1002/ eat.20976.

Stoltenberg, S. F., Christ, C. C., \& Highland, K. B. (2012b). Serotonin system gene polymorphisms are associated with impulsivity in a context dep endent manner. Progress in Neuro Psychopharmacology and Biological Psychiatry, 39, 182-191. https://doi.org/10.1016/j.pnpbp.2012.06.012.

Sugden, K., Arseneault, L., Harrington, H., Moffitt, T. E., Williams, B., \& Caspi, A. (2010). Serotonin transporter gene moderates the development of emotional problems among children following bullying victimization. Journal of the American Academy of Child E Adolescent Psychiatry, 49, 830840. https://doi.org/10.1016/j.jaac.2010.01.024.

Templeton, A. R. (2000). Epistasis and complex traits. In J. B. Wolf, E. D. Brodie, \& M. J. Wade (Eds.), Epistasis and the evolutionary process (Vol. 118, pp. 41-57). New York: Oxford University Press. https://doi.org/10.1046/j.1439-0388.2001.0185b.x.

Tiggemann, M., \& Slater, A. (2001). A test of objectification theory in former dancers and non-dancers. Psychology of Women Quarterly, 25, 57-64. https://doi.org/10.1111/1471-6402.00007.

Tucker, L. R., \& Lewis, C. (1973). A reliability coefficient for maximum likelihood factor analysis. Psychometrika, 38, 1-10. https://doi.org/10.1007/BF02291170.

Turecki, G., Brière, R., Dewar, K., Lesage, A., Séguin, M., Chawky, N., . . Rouleau, G. A. (2000). "Prediction of level of serotonin 2A receptor binding by serotonin receptor 2A genetic variation in postmortem brain samples from subjects who did or did not commit suicide": Reply. The American Journal of Psychiatry, 157, 1710-1711. https://doi.org/10.1176/appi.ajp.157.10.1710-a.

Urwin, R. E., \& Nunn, K. P. (2005). Epistatic interaction between the monoamine oxidase a and serotonin transporter genes in anorexia nervosa. European Journal of Human Genetics, 13, 370-375. https://doi.org/10.1038/sj.ejhg.5201328.

Wendland, J. R., Martin, B. J., Kruse, M. R., Lesch, K. P., \& Murphy, D. L. (2006). Simultaneous genotyping of four functional loci of human SLC6A4, with a reappraisal of 5-HTTLPR and rs25531. Molecular Psychiatry, 11, 224-226. https://doi.org/10.1038/sj.mp. 4001789.

Yilmaz, Z., Hardaway, J. A., \& Bulik, C. M. (2015). Genetics and epigenetics of eating disorders. Advances in Genomics and Genetics, 5, 131-150. https://doi.org/10.2147/AGG.S55776.

Zalsman, G., Huang, Y. Y., Oquendo, M. A., Burke, A. K., Hu, X. Z., Brent, D. A., . . Mann, J. J. (2006). Association of a serotonin transporter gene promoter region (5-HTTLPR) polymorphism with stressful life events and severity of depression. American Journal of Psychiatry, 163, 1588-1593. https://doi.org/10.1176/ajp.2006.163.9.1588.

Zhou, Z., Zhu, G., Hariri, A. R., Enoch, M. A., Scott, D., Sinha, R., . . Hodgkinson, C. A. (2008). Genetic variation in human NPY expression affects stress response and emotion. Nature, 452, 997-1001. https://doi.org/10.1038/nature06858. 
Supplementary material for Sullivan, G. A., Gervais, S. J., Brock, R. L., and Stoltenberg, S. F. (2019). Social responsiveness and objectification: The moderating roles of serotonin transporter and serotonin receptor 2A genotypes in an objectification theory model of disordered eating. Sex Roles. Scott Stoltenberg, University of Nebraska-Lincoln. Email: sstoltenberg2@unl.edu

\section{Supplemental DNA Processing Methods}

DNA was extracted from lysed buccal cells using the DNeasy Blood and Tissue Kit (Qiagen Inc, Valencia, California, USA). Polymerase Chain Reaction (PCR) was used to amplify the 5-HTTLPR and rs25531 polymorphisms using $25 \mu \mathrm{l}$ volume reactions containing 20ng of DNA, 1X GoTaq Master Mix (Promega, Madison, Wisconsin, USA), and $10 \mu \mathrm{M}$ each of forward and reverse primers: 5-TCCTCCGCTTTGGCGCCTCTTCC-3' and 5'-TGGGGGTTGCAGGGGAGATCCTG-3' (Wendland et al., 2006). The PCR amplification conditions followed previously recommended standards (Wendland et al., 2006). Restriction enzyme digest was used to recognize the rs25531 polymorphism by adding HpaII (New England BioLabs, Ipswich, Massachusetts, USA) to $15 \mu \mathrm{l}$ of the PCR product and incubating overnight at $37^{\circ} \mathrm{C}$. Gel electrophoresis was performed on a $2.5 \%$ agarose gel and visualized under UV light with SybrSafe stain. Two independent coders viewed the gels to make genotype calls, and any discrepancies were analyzed again and counted as missing data if no agreement was reached. Participants with highest functioning SLC6A4 genotypes (L/L on 5-HTTLPR and A/A on rs $\left.25531 ; \mathrm{L}^{\prime} / \mathrm{L}^{\prime}\right)$ were grouped for analysis and compared to anyone carrying a low-functioning allele ( $\mathrm{S}$ on 5-HTTLPR and/or G on rs25531; $\mathrm{S}^{\prime} / \_$). 
Table 1s: Univariate statistics for each combination of genotypes

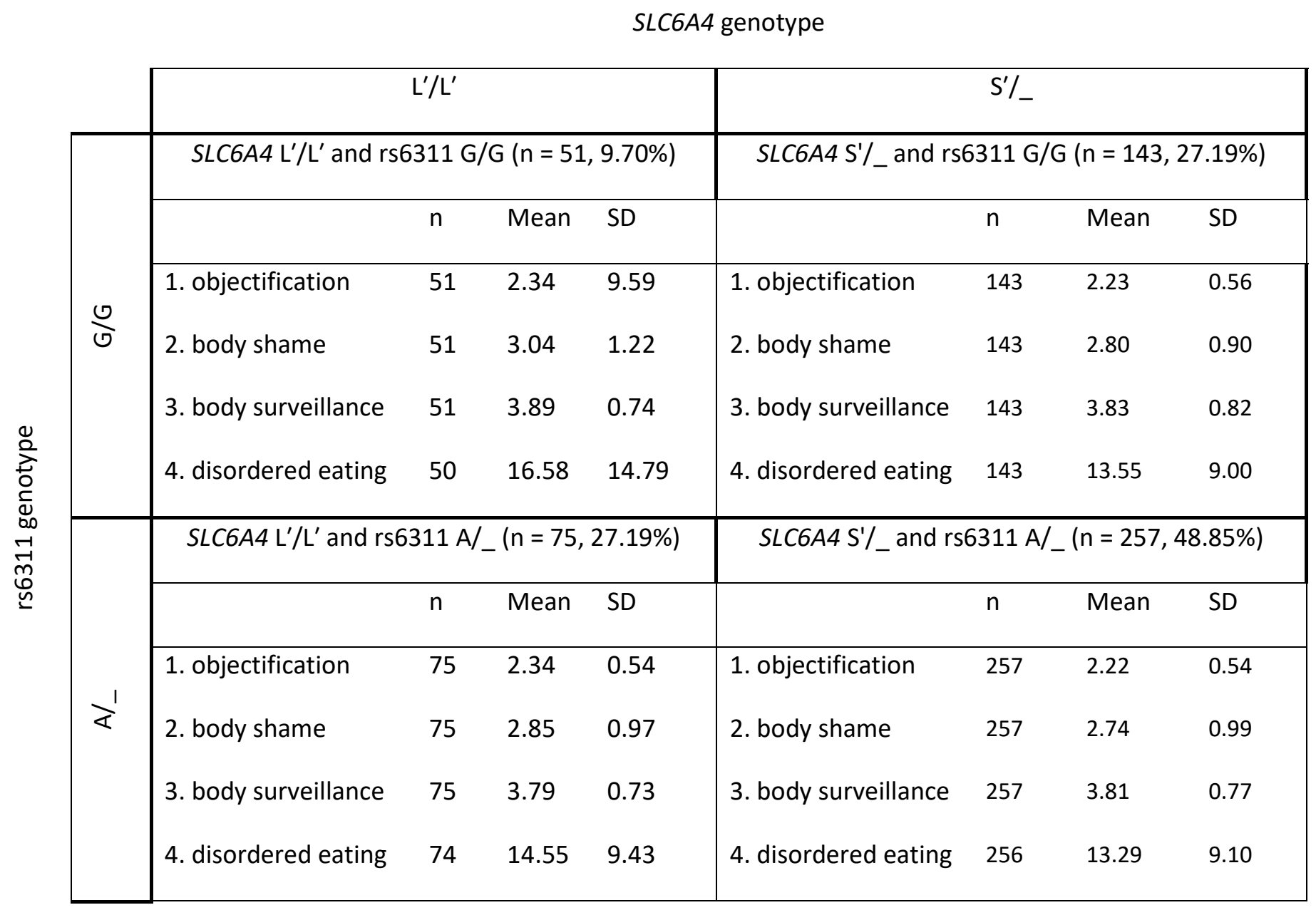




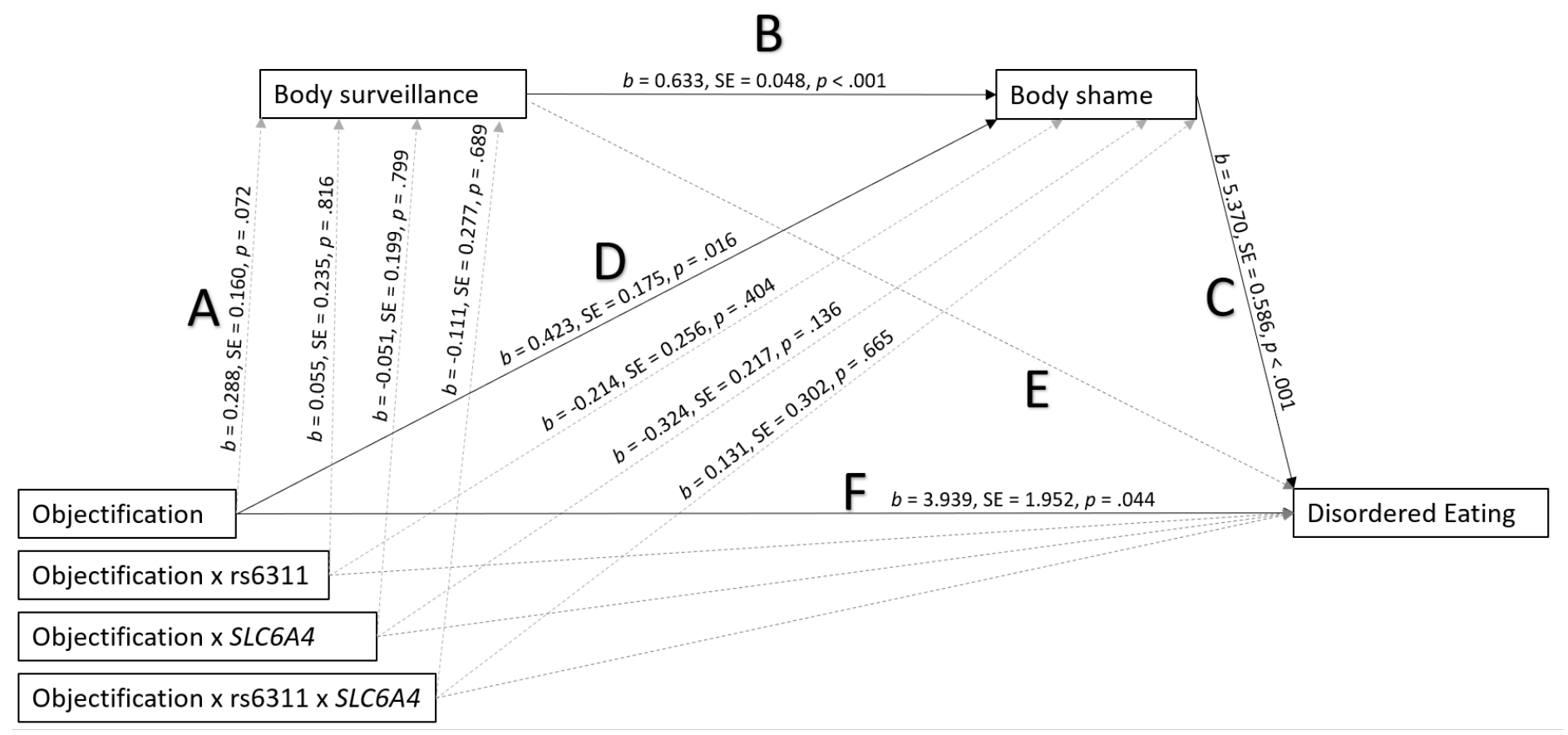

Figure 1s. Reduced model omitting nonsignificant interactions. We conducted a follow-up analysis removing nonsignificant genetic interactions from the model. When constraining the later paths (B, C, and E) to be the same across genotype, the genetic moderation was no longer present. Specifically, there was still evidence for the indirect effect of objectification on disordered eating via body shame, but this pathway did not vary as a function of genotype. Even subtle variation in specific paths within the larger model as a function of moderators might not reach statistical significance but can ultimately contribute to significant variation in overall indirect effects (Hayes, 2013); this might be the case in the present study. Indeed, in the full model (i.e., the model with all paths varying as a function of genotype), we found that the indirect effect of objectification on disordered eating via body shame did vary as a function of genotype. The global fit of the reduced model was adequate based on the CFI $=1.00$ (value of .90 or higher indicates adequate fit; Bentler, 1990), TLI $=1.126$ (value of .90 or higher indicates adequate fit; Tucker-Lewis, 1973), RMSEA <.001, 90\% CI [.000, .096] (values greater than .10 indicate poor fit; Browne \& Cudeck, 1992), SRMR $>.001$. The model accounted for $4.3 \%$ of the variance in body surveillance, $\mathrm{SE}=.017, \mathrm{p}=.013,30.6 \%$ of the variance in body shame, $\mathrm{SE}=.033, \mathrm{p}<.001$, and $26.5 \%$ of the variance in disordered eating, $\mathrm{SE}=.033, \mathrm{p}<.001$. Notably, the full model and reduced model both demonstrated adequate global fit and explained similar proportions of variance in the endogenous variables. 